\title{
Experiências e Expectativas em Práticas de Atividades Físicas de Pessoas com Anorexia Nervosa
}

\author{
Gisele Cerqueira Cumming* \\ Maria da Consolação Gomes Cunha Fernandes Tavares ${ }^{* *}$ \\ Angela Nogueira Neves Betanho Campana*** \\ Celso Garcia Júnior ${ }^{* * * *}$
}

\begin{abstract}
Resumo: Através de um estudo exploratório descritivo de cunho qualitativo, foram investigadas as experiências motoras em pessoas com anorexia nervosa, explorando seus motivos, suas expectativas, sua relação com o exercício no curso do transtorno e o papel do professor de educação física. Os dados reforçam a necessidade de proporcionar um ambiente seguro, de respeito às individualidades e auxílio no reconhecimento dos limites e das sensações corporais em propostas de atividades físicas para pessoas com anorexia nervosa.
\end{abstract}

Palavras-chave: Anorexia Nervosa. Atividade Motora. Terapia por Exercício

\section{INTRODUÇÃo}

A Anorexia Nervosa (A.N) é um transtorno alimentar caracterizado por importante perda de peso, amenorréia (no caso de mulheres), e perturbação no modo de vivenciar o peso ou a forma do corpo. Fatores familiares, psicológicos, socioculturais e fisiológicos interagem entre si de forma complexa de modo a predispor, a precipitar e/ou a manter o transtorno. A AN pode ser entendida, sob o

\footnotetext{
* Graduada em Educação Física - FEF/UNICAMP. Faculdade de Educação Física UNICAMP. Campinas, SP, Brasil. E-mail: cumming.gi@gmail.com>

** Livre Docente em Imagem Corporal. Docente do Departamento de Estudos de Atividade Física Adaptada. Faculdade de Educação Física. UNICAMP. Campinas, SP, Brasil. E-mail: mcons@fef.unicamp.br

*** Mestre em Educação Física, Adaptação e Saúde. Doutoranda em Educação Física, Adaptação e Saúde - FEF/UNICAMP. Bolsista CNPq, SP, Brasil.E-mail: angelanneves@yahoo.com.br> **** Mestre em Ciências Médicas. Psiquiatra do Departamento de Psicologia Médica e Psiquiatria. FCM/ UNICAMP. Campinas, SP, Brasil.E-mail: celsojr@unicamp.br
} 
aspecto da experiência corporal, como a expressão possível de um corpo marcado pela incompletude de seus limites corporais. Fica escrita no corpo a invasão continuamente sofrida ou a falta de empatia que não pode ser dita com palavras. A recusa do alimento e o emagrecimento que marca o corpo é o que se pode ver dessa angústia, o que chama a atenção (CAMPANA, 2007).

A cada dia, as pessoas com AN vivenciam um medo doentio de engordar e experienciam uma grande necessidade de controle sobre o peso e a forma do corpo. Dietas exíguas auto impostas, uso de laxantes, diuréticos e indução de vômito são estratégias usadas para manter o peso, o corpo e o medo sob controle. A atividade física também pode ser, para muitas pessoas com AN, uma dessas estratégias, métodos para perder e controlar peso (ASSUNÇÃO; CORDÁS; ARAÚJO, 2002). Os exercícios são praticados, frequentemente de maneira ritualizada e excessiva, obrigatória. O objetivo é, muitas vezes, alcançar um corpo ideal condizente com os padrões de beleza, deixando de lado as sensações internas. Os exercícios exaustivos são conduzidos de forma a "queimar" as poucas calorias que se permitem ingerir. Essa dependência do exercício é descrita por Assunção, Cordás e Araújo (2002) como um quadro secundário dos transtornos alimentares, tendo como único objetivo a perda/controle do peso.

Com o propósito de inibir o uso do exercício em excesso como uma estratégia de perda de peso das pacientes, tornou-se decisão clínica recorrente restringir toda atividade física no curso do transtorno e diversos estudos reiteravam tal prática. (DAVIS et al., 1994, 1997; HECHLER et al., 2005). Paralelamente à restrição da prática de exercícios físicos para pessoas com transtornos alimentares, ocorreram descobertas a respeito de efeitos positivos da prática de atividade física no curso de tratamento desses transtornos.

Pesquisadores que estudaram a questão da atividade física em pessoas com Transtornos Alimentares elaboraram métodos e meios de treinamento específicos (THIEN et al., 2000; BEUMONT et al., 1994) e encontraram benefícios da prática de atividades físicas supervisionada, tanto no campo fisiológico das capacidades físicas

Movimento, Porto Alegre, v. 15, n. 02, p. 69-85, abril/junho de 2009. 
(TOKUMURA et al., 2003; TOUYZ et al., 1984), quanto em relação aos aspectos emocionais e sociais (CARRARO et al., 1998).

Encontramos, então, duas vertentes da relação das atividades físicas com os transtornos alimentares: a prática excessiva e descontrolada de pessoas com algum Transtorno Alimentar (TA) como método para perder peso e a possível intervenção com atividades supervisionadas, nem sempre por professores de educação física, em conjunto com o atendimento clínico.

$\mathrm{Na}$ nossa realidade brasileira, a natureza dessa relação entre exercício físico e TA ainda é obscura. Nos três grandes centros públicos brasileiros de tratamento, o Ambulim, na USP; o Proata, na Unifesp e o Ambulatório de transtornos alimentares, na Unicamp, há profissionais de educação física entre seus pesquisadores, mas a inserção de exercícios físicos na dinâmica do tratamento ainda é um caminho a ser percorrido. Neste âmbito, é relevante investigar como esta relação entre exercícios e atividade física nos TA se estabelece no Brasil.

Para começar a preencher esta lacuna, esta pesquisa teve como objetivo verificar entre as pacientes com Anorexia Nervosa que frequentam o Ambulatório de Transtornos Alimentares da Unicamp (1) quais os motivos que determinam o gostar ou não de atividades físicas e (2) quais são as expectativas atuais desta população estudada quanto à prática de atividade física.

\section{Metodologia}

Este é um estudo descritivo, do tipo exploratório.

O estudo exploratório é caracterizado pela aproximação a um determinado problema que ainda não foi abordado em profundidade. Gil (1989) comenta que os estudos exploratórios propiciam uma familiaridade com o problema, o tornando mais explícito, favorecendo assim o aprimoramento de ideias ou a descoberta de intuições, sendo o seu planejamento bastante flexível, contemplando, dessa forma, os mais variados aspectos relativos ao fato estudado.

Movimento, Porto Alegre, v. 15, n. 02, p. 69-85, abril/junho de 2009. 
Este estudo foi aprovado pelo Comitê de Ética em pesquisa da Faculdade de Ciências Médicas da Universidade Estadual de Campinas (parecer número 564/2006).

\subsection{ANÁLISE}

No âmbito do estudo descritivo, o objetivo é descrever as características de um determinado grupo de pessoas ou um fenômeno, procurando identificar o perfil desse grupo, as relações entre as variáveis ou conceber uma nova abordagem do fenômeno (GIL, 1989).

Sob esta perspectiva, a análise foca-se em descrever as respostas dadas ao questionário, agregando as similaridades, apontando diferenças e singularidades. Em complementação à descrição da realidade do grupo, procuramos estabelecer relações com a situação deste grupo frente aos achados da bibliografia.

\subsection{SUJEITOS}

Participaram da pesquisa oito pacientes do Ambulatório de Transtornos Alimentares do Hospital de Clínicas (HC) da Unicamp diagnosticadas com Anorexia Nervosa, de acordo com os critérios do DSM-IV. Todas as voluntárias eram do sexo feminino e suas idades variavam entre 15 e 30 anos. Vale a ressalva de que, no período do estudo, o Ambulatório atendia 9 casos de Anorexia Nervosa: a paciente que não participou da pesquisa assim o fez por estar internada na época do estudo, um dos critérios de exclusão inicialmente previstos. Todas as demais pacientes encontravam-se em tratamento ambulatorial e eram acompanhadas semanalmente pela equipe multidisciplinar do referido ambulatório.

\subsection{INSTRUMENTOS}

Questionário de experiências motoras: elaborado especialmente para este estudo, o questionário dividia-se em duas partes compostas por questões abertas e fechadas. A primeira parte focava-se nas experiências motoras - brincadeiras de rua, educação física escolar, prática esportiva - antes do início da AN. Na segunda parte, as voluntárias

Movimento, Porto Alegre, v. 15, n. 02, p. 69-85, abril/junho de 2009 
poderiam descrever o que praticavam e o que sentiam quando faziam exercícios, depois de diagnosticado o transtorno alimentar. Questionamos ainda sobre o uso de exercícios como método de controle de peso e expectativas atuais sobre a atividade física.

\subsection{Procedimentos}

O questionário foi submetido a julgamento por duas profissionais, que trabalharam independentemente entre si. Uma era professora universitária e médica fisiatra com formação em psicanálise. A outra era profissional de educação física, especialista em prescrição de atividade física na promoção da saúde. Os pesquisadores discutiram as considerações que as profissionais fizeram ao instrumento e as consideradas relevantes foram acatadas.

Em seguida, o questionário foi submetido a um estudo piloto. Preferimos utilizar a técnica projetiva de terceira pessoa, preservando a população alvo. Este é um método no qual se pergunta ao respondente porque uma terceira pessoa fez algo ou o que essa terceira pessoa acha de determinado assunto. Espera-se que o respondente transfira suas atitudes a essa terceira pessoa - no caso, mulheres com Anorexia Nervosa (ZIKMAND, 2006). Após ser julgado por dez pessoas saudáveis, do sexo feminino, da mesma faixa etária que a população alvo do instrumento final, o questionário mostrou-se adequado, não necessitando de ajustes adicionais.

A coleta de dados foi conduzida pela pesquisadora principal e realizada no Ambulatório de Psiquiatria do $\mathrm{HC}$ - Unicamp, durante os meses de abril e maio/2007.

Inicialmente, todas as participantes assinaram o termo de consentimento livre e esclarecido, assim como os responsáveis das voluntárias menores de idade. Cada uma das voluntárias teve o tempo necessário para preencher o questionário, individualmente, acompanhado pela pesquisadora. Esta não interferiu no processo de preenchimento das respostas. As voluntárias menores de idade responderam o questionário desacompanhada dos pais, apenas na presença da pesquisadora. Todas preencheram o questionário num local mais preservado, a fim de garantir seu conforto e sigilo de suas respostas.

Movimento, Porto Alegre, v. 15, n. 02, p. 69-85, abril/junho de 2009. 


\section{ANÁLISE dOS RESULTADOS}

Procuramos estabelecer um novo olhar para a relação entre a atividade física e a Anorexia Nervosa baseada no interesse e nas sensações das pacientes, fenômeno que não pode ser descrito por números. Para a descrição das informações, elaboramos quatro grandes grupos de organização das respostas: (1) aderência aos exercícios físicos, (2) relações entre a AN e a prática de exercício físico, (3) influências do profissional de educação física e (4) expectativas atuais sobre o exercício físico. Foram inseridas algumas falas das respondentes, apenas com o intuito de ilustrar o cenário descrito.

\subsection{AdERÊNCIA AOS EXERCÍCIOS FÍSICOS}

Quando pensaram num tempo precedente ao transtorno alimentar, muitas voluntárias citaram por livre escolha em suas brincadeiras infantis, experiências que envolviam uma ação de mais pessoas (ex.: pic-esconde, pega-pega etc.). Não havia uma unanimidade na apreciação dessas brincadeiras; elas eram, por algumas respondentes, apreciadas e por outras não. Por outro lado, os jogos simbólicos foram também citados, e estiveram apenas entre as atividades preferidas das respondentes.

Nas atividades de aula de educação física, os jogos desportivos coletivos também apareceram como atividades apreciadas por algumas respondentes, mas não por outras. Entretanto, destacamos uma preferência pelas atividades de ginástica e alongamento. $\mathrm{Na}$ academia ou no clube, atividades individuais como musculação e corrida também dividiram preferências, com algumas respondentes gostando e outras rechaçando a prática. Nessa categoria, atividades como abdominais e ginástica localizada eram apreciadas por todas. As atividades rítmicas (danças, ginástica etc.) também aparecem apenas como atividades preferidas.

No momento de justificar o motivo para não gostar de determinadas atividades, notamos que o não saber jogar/ fazer, ou a suposta falta de habilidade em relação aos demais foi um ponto importante em muitos depoimentos, especialmente em relação aos esportes/ jogos coletivos:

Movimento, Porto Alegre, v. 15, n. 02, p. 69-85, abril/junho de 2009. 
Não gostava dos esportes de quadra, com bola por
que nunca me dei bem, as outras crianças eram mais
espertas, eu tinha medo, tinha muita gente, é muito
bruto. (02)
Não gostava de vôlei por que não tenho nenhuma
habilidade com a bola. (07)
Não gostava de basquete por que não sabia jogar. (08)

Parece então haver uma relutância em se engajar em atividades em que há uma característica que remeta a desempenho, competição e comparação com outras pessoas. Esportes/ jogos coletivos podem, de certa maneira, evidenciar tanto as habilidades quanto os erros individuais. Alguns autores descrevem o perfeccionismo como característica marcante da personalidade de pessoas com Anorexia Nervosa. (MORGAN; VECCHIATTI; NEGRÃO, 2002; ABREU; CANGELLI, 2004). Assim, a exposição negativa neste modelo de atividade pode não ser agradável a algumas pessoas com $\mathrm{AN}$.

Outro grande grupo de motivos remete a sensações e a sentimentos. Vergonha, falta de afinidade, frustração, obrigação em fazer e medo foram palavras usadas para descrever experiências que classificaram como ruins: " [...] Não gostava de atividades como vôlei, basquete, musculação. Porque, de certa forma, me sentia envergonhada e por não ter mesmo afinidade com estas." (01)

Em relação às atividades preferidas, observamos que bons eram os exercícios, os esportes e as brincadeiras que podiam experimentar em um ambiente seguro, confiável. Este ambiente não necessariamente tem de ser usufruído de forma particular, mas parece que um grupo de amigos receptivos, também constrói um ambiente favorável: "Eu gostava de nadar na piscina da minha avó, pois podia nadar a vontade, sozinha, sem competição com ninguém." (02 )[...] "Eu gostava de queimada, porque podia jogar com todos os meus amigos." (07)

Uma experiência podia ser apreciada quando proporcionava uma sensação de bem-estar. "Se sentir bem" não fica bem esclarecido, mas é algo como "[...] ficar tranquila, equilibrada" (01). Entretanto, vale a atenção para uma característica identificada nas respostas: quando se remetem ao momento presente, tranquilidade tanto vem

Movimento, Porto Alegre, v. 15, n. 02, p. 69-85, abril/junho de 2009. 
de uma sensação de harmonia interior quanto da sensação de estar gastando energia e controlando o peso. Se, à primeira vista, as pacientes relacionam o exercício como uma prática que as tiram da dinâmica da doença, num movimento ambivalente, o exercício físico se torna um meio de manejar o corpo para alcançar e manter a magreza. Esta relação nos remete à próxima categoria.

\subsection{RELAÇÕES ENTRE A AN E A PRÁtICA DE EXERCíCIO FÍSICO}

Com o início do transtorno, a relação com a atividade física tornou-se ambígua em muitos relatos. Com o transtorno alimentar em curso, fazer exercícios para gastar calorias provoca alívio do medo de engordar: [...] "Eu gosto de musculação porque dá uma desenvolvida no corpo." (04) [...] "Natação e corrida são o que eu gosto porque me faz perder peso." (08)

Configura-se aí uma razão para a adesão a programas de exercícios físicos: promover controle do peso e do corpo. Apesar do alívio, este tipo de atividade parece ser realizado de modo obrigatório, como se não houvesse outra opção: "Faço atividade física em excesso para controlar meu peso, mas com um sentimento de obrigação" (01).

Se em alguns relatos aparece esta ligação direta entre exercício e controle do corpo, ela não se estabelece como uma norma, ou seja, não necessariamente; o "bem estar" sentido é resultado de calorias gastas; não se faz exercícios apenas para perder ou manter o peso. Assim, existem atividades que parecem ter sido desvinculadas do controle do peso, do sentimento de obrigação. A caminhada e a dança aparecem na maioria dos relatos associadas aos sentimentos de leveza, liberdade, calma e alegria:

Gosto de caminhada porque é a única coisa que realmente faço que me traz uma sensação de leveza e liberdade. (02)

Gosto muito de caminhar e dançar por que distrai a mente, entra em contato com outras pessoas e me acalma. (03)

Observamos assim, a partir do olhar que as voluntárias transmitiram em seus relatos, que a atividade física pode ter um papel de

Movimento, Porto Alegre, v. 15, n. 02, p. 69-85, abril/junho de 2009. 
manutenção do transtorno, já que, se praticado de maneira exaustiva, auxilia no controle do peso, mas também pode ter um papel terapêutico, pois remete a sentimentos que acalmam e ajudam no contato com outras pessoas. Tais funcionalidades da atividade física dependem, então, do momento e do objetivo com o qual é praticado.

Entre os relatos, podemos distinguir uma ligação entre duas atividades específicas e o início do transtorno alimentar. A musculação foi associada por duas voluntárias ao início do transtorno alimentar. A voluntária 06 considerou que a musculação provocou mudanças no seu corpo, o que a deixou assustada. A voluntária 04 disse que sua vontade de emagrecer mais e mais cresceu na medida em que seus treinos de musculação aumentavam. A voluntária 01 trouxe uma outra perspectiva sobre esta relação do exercício físico e o início da $\mathrm{AN}$ : ao relatar que associa o ballet com o início de seu transtorno alimentar, fica claro que não foi o ballet em si, mas as expectativas que recaiam sobre ela alcançar o corpo magro e esguio da bailarina reforçada na escola de dança e em sua família. Nos outros relatos, não houve uma ligação predominante entre a prática esportiva e o início do transtorno alimentar, ou seja, não foi reconhecido que realizar exercícios físicos configura-se sempre como um fator predisponente e/ou desencadeante da AN.

\subsection{O PROFESSOR DE EDUCAÇÃO FISICA}

Em apenas um relato, o professor de educação física foi literalmente citado. A voluntária 02 relatou que uma experiência, marcada pelo desrespeito de seu professor de educação física, a fez sentir mais vergonha de seu corpo, mais desengonçada, enfatizando a sensação de ser menos ágil que suas colegas, menos adequada. O que vinha a público eram um desgosto profundo por todo e qualquer exercício que pudesse ser associado à educação física escolar, especialmente os desportos coletivos.

\subsection{EXPECTATIVAS ATUAIS}

Ao escolher atividades que gostariam de praticar hoje, as atividades individuais e as atividades com baixo impacto foram consideradas boas e relacionadas por todas as respondentes, com sentimentos

Movimento, Porto Alegre, v. 15, n. 02, p. 69-85, abril/junho de 2009. 
de calma, equilíbrio e leveza. Nos relatos, podemos identificar uma tendência de escolha de atividades que promovam estes sentimentos e que já são conhecidas, em detrimento de novas experiências ou da retomada de alguma prática que no passado possa ter sido frustrante.

Parece, então, que se espera que o exercício físico seja um espaço de suporte, em que elas possam deixar o corpo fruir de num ambiente conhecido, seguro, e que, via de regra, não desperta sentimentos e sensações desagradáveis. O espaço da atividade física, configura-se em seus discursos como uma promessa de alívio, de ser mais um instrumento em seu processo de tratamento.

O quadro 1, a seguir, foi elaborado a partir de um olhar mais individual para cada voluntária, permitindo, ao mesmo tempo, comparar as respostas e observar tendências de maneira objetiva:

\begin{tabular}{|c|c|c|c|c|c|}
\hline \multirow{2}{*}{ 告: } & \multicolumn{2}{|c|}{ Antes do início da Anorexia } & \multirow{2}{*}{$\begin{array}{c}\text { Experiência corporal } / \\
\text { início da Anorexia } \\
\text { Nervosa }\end{array}$} & \multicolumn{2}{|c|}{ Durante a Anorexia } \\
\hline & $\begin{array}{l}\text { Mais gostava: } \\
\text { motivos }\end{array}$ & $\begin{array}{l}\text { Menos gostava: } \\
\text { motivos }\end{array}$ & & $\begin{array}{l}\text { Atividade atual } \\
\text { que mais gosta }\end{array}$ & $\begin{array}{l}\text { Métodos de controle } \\
\text { do peso }\end{array}$ \\
\hline 1 & $\begin{array}{c}\text { Ballet/atriz: } \\
\text { gostava de arte, } \\
\text { dança, de se ver no } \\
\text { espelho }\end{array}$ & $\begin{array}{l}\text { Vôlei, basquete: } \\
\text { vergonha, falta de } \\
\text { afinidade }\end{array}$ & $\begin{array}{l}\text { Ballet: representação } \\
\text { social da bailarina } \\
\text { magra; relação com a } \\
\text { mãe muito vaidosa }\end{array}$ & $\begin{array}{c}\text { Dança, atividades } \\
\text { na natureza: prazer, } \\
\text { criatividade, } \\
\text { equillbrio, felicidade }\end{array}$ & $\begin{array}{c}\text { Controle de alimentos - } \\
\text { prisão } \\
\text { Atividade Física - } \\
\text { obrigação } \\
\text { Vômito - depressão }\end{array}$ \\
\hline 2 & $\begin{array}{l}\text { Nadar na piscina da } \\
\text { avó: privacidade; } \\
\text { sem competição }\end{array}$ & $\begin{array}{l}\text { Jogos Desportivos } \\
\text { Coletivos: fracasso, } \\
\text { medo, brutalidade }\end{array}$ & \begin{tabular}{|c|} 
Esportes: vergonha e \\
timidez, desrespeito por \\
parte de prof. de \\
Educação Física \\
\end{tabular} & $\begin{array}{c}\text { Caminhada: leveza } \\
\text { e liberdade }\end{array}$ & \begin{tabular}{|c|} 
Restrição - sofrimento, \\
dor, raiva \\
Vômito - nojo, \\
frustração, medo
\end{tabular} \\
\hline 3 & $\begin{array}{l}\text { Alongamento: } \\
\text { bem-estar, ânimo } \\
\text { para outras } \\
\text { atividades }\end{array}$ & $\begin{array}{l}\text { Vôlei: fracasso, } \\
\text { desinteresse }\end{array}$ & Não & $\begin{array}{c}\text { Caminhada, dança: } \\
\text { distração, calma, } \\
\text { socialização }\end{array}$ & $\begin{array}{c}\text { Comer pouco - irritação } \\
\text { Atividade Física - alívio } \\
\text { para perder peso }\end{array}$ \\
\hline 4 & $\begin{array}{c}\text { Musculação: } \\
\text { definição do corpo }\end{array}$ & Basquete: brutalidade & $\begin{array}{l}\text { Musculação: vontade } \\
\text { de emagrecer mais }\end{array}$ & $\begin{array}{l}\text { Caminhada: } \\
\text { relaxamento; } \\
\text { Musculação: } \\
\text { definir o corpo }\end{array}$ & $\begin{array}{l}\text { Nutrição (?) } \\
\text { Psicologia (?) } \\
\text { Psiquiatria (?) }\end{array}$ \\
\hline 5 & Basquete:? & $\begin{array}{l}\begin{array}{l}\text { Jogos e brincadeiras } \\
\text { de rua: desinteresse }\end{array} \\
\end{array}$ & Não & Basquete:? & $\begin{array}{c}\text { Não respondeu: "questão } \\
\text { muito pessoal" }\end{array}$ \\
\hline 6 & $\begin{array}{l}\text { Vôlei: divertido, } \\
\text { dinâmico }\end{array}$ & $\begin{array}{c}\text { Musculação - } \\
\text { modificação estrutural } \\
\text { do corpo }\end{array}$ & $\begin{array}{l}\text { Musculação: maior } \\
\text { preocupação com o } \\
\text { peso, gordura }\end{array}$ & $\begin{array}{l}\text { Dança, vôlei: mexe } \\
\text { muito com o corpo }\end{array}$ & Não comer: angústia \\
\hline 7 & Queimada: divertido & Vôlei: fracasso & $\begin{array}{c}\text { Preocupação constante } \\
\text { com o corpo }\end{array}$ & $\begin{array}{c}\text { Dança e } \\
\text { caminhada: ? }\end{array}$ & $\begin{array}{c}\text { Não comer - } \\
\text { autocontrole } \\
\text { Laxante - bem-estar }\end{array}$ \\
\hline 8 & Peteca:? & Basquete: fracasso & Não & $\begin{array}{l}\text { Atividades na } \\
\text { natureza: adora o } \\
\text { ar do campo }\end{array}$ & $\begin{array}{c}\text { Dieta - culpa } \\
\text { Atividade Física (natação } \\
\text { e corrida) - perder peso }\end{array}$ \\
\hline
\end{tabular}

Quadro1. Resumo dos Casos

Movimento, Porto Alegre, v. 15, n. 02, p. 69-85, abril/junho de 2009. 


\section{Dıscussão}

Após a análise descritiva das respostas dos questionários, deparamo-nos com uma variedade de atividades físicas e motivos para gostar e não gostar de exercícios físicos. Gabler (1989) estabelece cinco grandes grupos de motivos que determinam o engajamento em atividades físicas/esportes: motivos relacionados à prática esportiva em si e relacionadas do "eu", motivos relacionados à prática esportiva em si e ao social, motivos relacionados aos resultados da prática esportiva e ao "eu", motivos relacionados ao resultado da prática esportiva e ao social e motivos relacionados à prática esportiva como meio para outros fins e ao "eu". Em nosso grupo de entrevistadas, os motivos declarados estão, em sua maioria, agrupados neste último grande grupo. Praticam o exercício como um meio de alcançar outros benefícios - descontração, compensação, contatos, aproximações - e não por apenas fazer ou para fazer melhor que outros. A dança e a caminhada são as atividades mais praticadas atualmente pelas voluntárias da pesquisa. Essas atividades foram associadas a sentimentos tais como liberdade, leveza e relaxamento.

Não gostar parece estar intimamente relacionado a sentimentos e a sensações ruins experienciados anteriormente. Um ambiente competitivo e um profissional pouco adequado colaboram para que a vivência esportiva seja frustrante. Estes dois elementos - ambiente e profissional inadequados - podem levar a uma percepção equivocada pelo aluno de seu desempenho, considerando-o sempre ruim, insatisfatório. O exercício físico se torna um fardo, que é mais fácil de abandonar do que carregar. Os esportes coletivos e/ou de impacto, de maneira geral, foram marcados como preteridos, relacionados principalmente a sentimentos de vergonha, fracasso, medo e desinteresse.

Embora não tenha sido uma regra geral para todas as voluntárias da pesquisa, é marcante a semelhança das respostas sobre os sentimentos em relação aos esportes coletivos e às atividades rítmicas. Considerando que os sujeitos deste estudo são todos do sexo feminino, podemos nos remeter às questões históricas sobre as atividades das aulas de Educação Física. Atividades de impacto, esportes no geral, eram vistos como próprios para homens, pois ajudaria a desenvolver

Movimento, Porto Alegre, v. 15, n. 02, p. 69-85, abril/junho de 2009. 
a virilidade, já que o corpo do homem devia ser forte e resistente. Já a mulher, deveria praticar danças e ginásticas, atividades dotadas de movimentos dóceis e suaves, ditos femininos (SOUZA; ALTMAN, 1999). Esses traços e valores da ginástica higienista, educadora dos corpos, da Europa do século XIX (SOARES, 2000) permanecem, mesmo que implícita e subliminarmente até os dias de hoje. Isto que pode explicar, em parte, os sentimentos de vergonha e medo do fracasso de algumas voluntárias em relação aos esportes coletivos e à tranquilidade em engajar-se na prática de danças e de ginásticas.

Muitos programas de atividades físicas específicos para pessoas com Anorexia Nervosa encontrados até o presente momento focam seus objetivos, principalmente nos sintomas clínicos das pacientes, em especial, no ganho de peso e adesão à psicoterapia.

Touyz et al. (1984) propuseram um novo método de trabalho comportamental para o tratamento da AN. Durante nove semanas, compararam os efeitos do método convencional de tratamento com restrição total de atividade física e de um método leniente, com a possibilidade de caminhadas pela unidade de tratamento, em 65 pacientes, divididas nos dois grupos. Observou-se que não houve diferença significativa de ganho de peso entre os dois grupos de tratamento. Além disso, constatamos que $24 \%$ das pacientes do grupo do método mais brando, dito leniente, e $10 \%$ das pacientes do método convencional mostraram-se cooperativas com o grupo de cuidadores ao longo das seis semanas. Ademais, as pacientes do método leniente tornaram-se mais predispostas à psicoterapia.

Beumont et al. (1994) realizaram uma pesquisa, revendo o papel da atividade física em excesso e propuseram um programa de exercícios assistidos, ressaltando que considerações, esclarecimentos e reflexões sobre os prejuízos consequentes dos excessos de exercícios sejam inseridos nos tratamentos dos transtornos alimentares.

Thien et al. (2000) propõem um programa de exercícios de três meses de duração para pacientes não hospitalizados com diferentes graduações de tipo de exercício, duração e nível da atividade. A intensidade da atividade física é dependente do índice de massa corporal (IMC) e o percentual de gordura $(\% \mathrm{G})$, e as atividades variam

Movimento, Porto Alegre, v. 15, n. 02, p. 69-85, abril/junho de 2009. 
entre exercícios de alongamento, resistidos e cardiovasculares. Este programa teve como objetivo ver o quanto a qualidade de vida do paciente melhora com a prática de exercícios, sem redução de gordura ou massa corporal. Foi possível concluir que nos 3 meses de experimento, o IMC e \%G aumentaram sem diferenças significativas entre os grupos, e que o grupo experimental apresentou melhor qualidade de vida, medido pelo SF-36, contrastando com a queda dos índices de qualidade de vida do grupo controle.

Tokumura et al. (2003) observaram por um período de um ano, 17 mulheres diagnosticadas com AN, procurando descobrir melhoras na capacidade aeróbia, quando submetidas a um programa de exercícios. Nove voluntárias, com peso estável e com $25 \%$ de gordura em sua massa corporal foram submetidas a 30 minutos de exercícios aeróbios e treinamento de força por 5 dias na semana. As oito demais voluntárias constituíram o grupo controle. Ao final dos 12 meses, concluíram que ambos os grupos aumentaram seu IMC e $\% \mathrm{G}$, sendo que o aumento ocorreu em um grau mais elevado no grupo experimental. Ambos aumentaram sua capacidade de trabalho aeróbio, mas o aumento do grupo controle foi estatisticamente não significativo, ao contrário do ocorrido com o grupo experimental.

Ao longo desses estudos, muito avançamos na compreensão dos benefícios da prática supervisionada da atividade física pela população com Transtornos Alimentares, reforçando sua importância como parte do tratamento.

Também é igualmente importante considerar a pessoa com Anorexia Nervosa como um sujeito que diz com o corpo o que não consegue formular com palavras. Os sintomas de emagrecimento, teimosia, obstinação, medo são expressões escritas na carne de uma identidade que procura recursos para se estruturar. Na ausência dos recursos, manter-se seguro nos movimentos estereotipados e no "não comer" passa ser uma saída para precaver-se de invasões, marcar seus limites e manter-se vivo. Conhecer o que se passa na realidade corporal de cada sujeito com Anorexia Nervosa é uma atitude respeitosa em relação ao sujeito, com histórias recorrentes de invasão e desvalorização.

Movimento, Porto Alegre, v. 15, n. 02, p. 69-85, abril/junho de 2009. 
Em outra linha de pensamento, encontramos em Carraro et al. (1998), uma pesquisa na qual os alvos principais do programa de atividades físicas relacionavam-se à identidade individual, às relações com as outras pacientes, às relações com o corpo e ao início da construção um conceito correto do uso da atividade física. Os autores conduziram uma pesquisa, em que 96 pacientes com transtornos alimentares foram submetidas a um programa de atividade física adaptada. Foram propostas atividades como dança, esportes adaptados, exercícios ginásticos, atividades de expressão e relaxamento, em grupos e individualmente. Os autores desta pesquisa consideram a atividade física como uma experiência emocional e corporal que pode ajudar a melhorar a autoestima, a dificuldade nas relações sociais, as capacidades físicas, entre outros aspectos. $\mathrm{O}$ foco não estava na performance, mas sim na experiência perceptiva - corporal que cada atividade física pode trazer.

Também encontramos Duesund e Skarderud (2003), que, em seu estudo exploratório com base teórica na fenomenologia, submeteram 7 mulheres com Anorexia Nervosa grave a um programa de atividades físicas adaptado para investigar se a interação social em atividades físicas poderia mover a atenção negativa que pessoas com anorexia nervosa têm em relação ao seu corpo para uma experiência mais profunda e subjetiva consigo mesma. As atividades eram não competitivas, desafiantes e deveriam focar no aspecto social e no relaxamento. As modalidades variavam entre atividades aquáticas, escalada indoor (parede de escalada), atividades de relaxamento, com bolas, esquiar, cavalgar, e caminhadas e trilhas na natureza. Os autores concluíram que a atividade física adaptada pode ser usada clinicamente no tratamento de pessoas com Anorexia Nervosa e encorajam futuros pesquisadores a estudarem mais essa questão.

Ao buscar compreender como a pessoa que sofre com Anorexia Nervosa se relaciona com as atividades físicas, seus desejos e expectativas, colocamos o indivíduo no centro desta questão, e, dessa maneira, podemos trazer a tona não apenas a preocupação com seu peso e formas corporais, mas também proporcionar ações que possibilitem cada sujeito reconhecer suas possibilidades e limitações, isto é, propiciar ao sujeito ter mais conhecimento de sua própria realidade.

Movimento, Porto Alegre, v. 15, n. 02, p. 69-85, abril/junho de 2009. 
Saber mais de si, saber mais concretamente o que o aflige, o que o deixa bem ajuda a estabelecer recursos para momentos estressantes e situações traumáticas.

\section{CONSIDERAÇõES FINAIS}

Buscamos, ao longo deste estudo, compreender quais significações a atividade física pode ter para pessoas com Anorexia Nervosa, bem com as sensações que determinadas atividades podem trazer-lhes.

A partir das reflexões apresentadas, acreditamos que um programa de atividades físicas para pessoas com Anorexia Nervosa deve propiciar um espaço para que a pessoa possa se sentir segura e confiante para se expressar corporalmente, construindo e reconstruindo bases que fortaleçam sua identidade corporal.

Seria irresponsabilidade desconsiderar os cuidados impostos pela condição física dessas pessoas, mas o mais importante é a postura sensível do profissional para perceber as necessidades tanto físicas quanto emocionais e ajudá-las no reconhecimento de suas sensações.

Encorajamos que novos estudos com a perspectiva do mesmo apresentado aqui sejam feitos com grupos maiores de pessoas com $\mathrm{AN}$ e com grupos de pessoas com outros transtornos alimentares, $\mathrm{o}$ que possibilitará a criação de programas de exercícios físicos adequados às expectativas desta população.

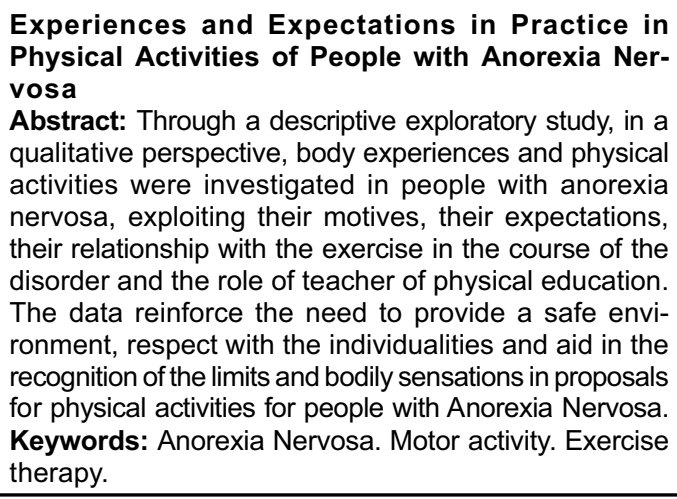

Movimento, Porto Alegre, v. 15, n. 02, p. 69-85, abril/junho de 2009. 
Experiencias y Expectativas en Prácticas de Actividades Físicas de Personas con Anorexia Nerviosa

Resumen: Através de un estudio exploratorio descriptivo de cuño cualitativo, fueron investigadas las experiencias motoras en personas con anorexia nerviosa, explorando sus motivos, sus expectativas, su relación con el ejercicio en desarrollo de trastorno y el rol del profesor de educación física. Los datos refuerzan la necesidad de proporcionar un ambiente seguro, de respeto a la individualidad y auxilio en el reconocimiento de límites y sensaciones corporales en propuestas de actividades físicas para personas con Anorexia Nerviosa.

Palabras Clave: Anorexia Nerviosa. Actividad motora. Terapia por ejercicio.

\section{REFERÊNCIAS}

ABREU, C. N. de; CANGELLI FILHO, R. Anorexia nervosa e bulimia nervosa: abordagem cognitivo-construtivista de psicoterapia. Revista de Psiquiatria Clínica, São Paulo, v.31, n..4, p. 177-183, 2004.

ASSUNÇÃO, S.S.M.; CORDÀS, T.A.; ARAÚJO, L.A.S.B Atividade Física e Transtornos Alimentares. Revista de Psiquiatria Clínica, São Paulo,v. 29, n.1, p. 4-13, 2002.

BEUMONT, P.J.V.; ARTHUR, B.; RUSSELL, J.D.; TOUYZ, S.W. Excessive physical activity in dieting disorder patients: Proposals for a supervised exercise program. International Journal of Eating Disorders, Hoboken, v.15, n.1, p.21-36, 1994.

CAMPANA, A N N B. Anorexia nervosa: o não comer e as marcas no corpo. In: TAVARES, MCGCF (org) O Dinamismo da Imagem Corporal. São Paulo: Manole, 2007.

CARRARO, A.; COGNOLATO, S.; FOIRELINI BERNARDIS, A.L. Evaluation of a program of adapted physical activity for ED patients. Eating and Weight Disorders, Roma, v.3, n.1, p.110-114, 1998.

DAVIS, C. et al. The role of physical activity in the development and maintenance of eating disorders. Psychological Medicine, Cambridge, v. 24, n.4, p.957 - 967, 1994.

DAVIS, C. et al. The prevalence of High - Level Exercise in the eating disorders: etiological implications. Comprehensive Psychiatry. Amsterdã, v. 38, n.06, p.321 - 326, 1997.

DUESUND, L.; SKÅRDERUD, F. Use the Body and Forget the Body: Treating Anorexia Nervosa with Adapted Physical Activity. Clinical Child Psychology and Psychiatry, Londres, v. 8, n.1, p. 57-72, 2003.

Movimento, Porto Alegre, v. 15, n. 02, p. 69-85, abril/junho de 2009. 
HECHLER, T. et al. How do clinical specialists understand the role of physical activity in eating disorders? European Eating Disorders Review, Oxford, v.13, n.2, p. $125-132,2005$

\section{GIL, A.C. Métodos e Técnicas de pesquisa social. São Paulo: Atlas, 1989}

GRABLER, H. O que os parceiros querem no esporte - e como isso pode ser reconhecido. In: DIECKERT, J. Ensinar e aprender na Educação Física. Rio de Janeiro: Livro Técnico, 1989.

MORGAN, C.M.; VECCHIATTI, I.R.; NEGRAO, A.B. Etiology of eating disorders: biological, psychological and socio cultural determinants. Revista Brasileira de Psiquiatria, São Paulo, v.24, supl.3, p.18-23, 2002

SOARES, C. L. Notas sobre a educação no corpo. Revista Educar, Curitiba, v.16, n.1, p.43-60, 2000.

SOUSA, E.S. de; ALTMANN, H. Meninos e meninas: expectativas corporais e implicações na educação física escolar. Caderno CEDES, Campinas, v. 19, n. 48, p. 52-68, 1999.

THIEN, V. et al. Pilot Study of a Graded Exercise Program for the Treatment of Anorexia Nervosa. International Journal of Eating Disorders, Hoboken, v.28, n. 1, p.101 - 106, 2000

TOKUMURA, $\mathrm{M}$ et al.. Prescribed exercise training improves exercise capacity of convalescent children and adolescents with anorexia nervosa. European Journal of Pediatrics, Leuven, v.162, n.6, p. 430-431, 2003.

TOUYZ, S.W. et al. A comparison of lenient and strict operant conditioning programmes in refeeding patients with anorexia nervosa. British Journal of Psychiatry, Londres, v.144, p.517- 520, 1984.

ZIKMAND, N. Princípios da Pesquisa em Marketing. São Paulo: Thompson, 2006

Pesquisa com financiamento do CNPq

Recebido em: 07/03/2008

Aprovado em: 16/02/2009

Movimento, Porto Alegre, v. 15, n. 02, p. 69-85, abril/junho de 2009. 